\title{
A reference data set for validating vapor pressure measurement techniques: homologous series of polyethylene glycols
}

\author{
Ulrich K. Krieger ${ }^{1}$, Franziska Siegrist ${ }^{1}$, Claudia Marcolli ${ }^{1}$, Eva U. Emanuelsson ${ }^{2}$, Freya M. Gøbel ${ }^{2}$, Merete Bilde ${ }^{2}$, \\ Aleksandra Marsh ${ }^{3}$, Jonathan P. Reid ${ }^{3}$, Andrew J. Huisman ${ }^{4}$, Ilona Riipinen ${ }^{5}$, Noora Hyttinen ${ }^{6}$, Nanna Myllys ${ }^{7}$, \\ Theo Kurtén ${ }^{6}$, Thomas Bannan ${ }^{8}$, Carl J. Percival ${ }^{8}$, and David Topping ${ }^{8}$ \\ ${ }^{1}$ Institute for Atmospheric and Climate Science, ETH Zürich, 8092 Zürich, Switzerland \\ ${ }^{2}$ Department of Chemistry, Aarhus University, 8000 Aarhus, Denmark \\ ${ }^{3}$ School of Chemistry, University of Bristol, BS8 1TS Bristol, UK \\ ${ }^{4}$ Chemistry Department, Union College, Schenectady, NY 12308, USA \\ ${ }^{5}$ Department of Environmental Science and Analytical Chemistry, Stockholm University, 10691 Stockholm, Sweden \\ ${ }^{6}$ Department of Chemistry, University of Helsinki, 00014 Helsinki, Finland \\ ${ }^{7}$ Department of Physics, University of Helsinki, 00014 Helsinki, Finland \\ ${ }^{8}$ Centre for Atmospheric Sciences, School of Earth, Atmospheric and Environmental Sciences, University of Manchester, \\ Manchester, M13 9PL, UK
}

Correspondence: Ulrich K. Krieger (ulrich.krieger@env.ethz.ch)

Received: 4 July 2017 - Discussion started: 6 July 2017

Revised: 14 November 2017 - Accepted: 17 November 2017 - Published: 8 January 2018

\begin{abstract}
To predict atmospheric partitioning of organic compounds between gas and aerosol particle phase based on explicit models for gas phase chemistry, saturation vapor pressures of the compounds need to be estimated. Estimation methods based on functional group contributions require training sets of compounds with well-established saturation vapor pressures. However, vapor pressures of semivolatile and low-volatility organic molecules at atmospheric temperatures reported in the literature often differ by several orders of magnitude between measurement techniques. These discrepancies exceed the stated uncertainty of each technique which is generally reported to be smaller than a factor of 2. At present, there is no general reference technique for measuring saturation vapor pressures of atmospherically relevant compounds with low vapor pressures at atmospheric temperatures. To address this problem, we measured vapor pressures with different techniques over a wide temperature range for intercomparison and to establish a reliable training set. We determined saturation vapor pressures for the homologous series of polyethylene glycols $\left(\mathrm{H}-\left(\mathrm{O}-\mathrm{CH}_{2}-\mathrm{CH}_{2}\right)_{n}-\mathrm{OH}\right)$ for $n=3$ to $n=8$ ranging in vapor pressure at $298 \mathrm{~K}$ from $10^{-7}$ to $5 \times 10^{-2} \mathrm{~Pa}$ and compare them with quantum chemistry calculations. Such a ho-
\end{abstract}

mologous series provides a reference set that covers several orders of magnitude in saturation vapor pressure, allowing a critical assessment of the lower limits of detection of vapor pressures for the different techniques as well as permitting the identification of potential sources of systematic error. Also, internal consistency within the series allows outlying data to be rejected more easily. Most of the measured vapor pressures agreed within the stated uncertainty range. Deviations mostly occurred for vapor pressure values approaching the lower detection limit of a technique. The good agreement between the measurement techniques (some of which are sensitive to the mass accommodation coefficient and some not) suggests that the mass accommodation coefficients of the studied compounds are close to unity. The quantum chemistry calculations were about 1 order of magnitude higher than the measurements. We find that extrapolation of vapor pressures from elevated to atmospheric temperatures is permissible over a range of about $100 \mathrm{~K}$ for these compounds, suggesting that measurements should be performed best at temperatures yielding the highest-accuracy data, allowing subsequent extrapolation to atmospheric temperatures. 


\section{Introduction}

Atmospheric oxidation of organic vapors can lead to lowvolatility and semivolatile organic compounds (LVOCs and SVOCs), which are multifunctional in nature with molar masses typically between 150 and $300 \mathrm{~g} \mathrm{~mol}^{-1}$ and saturation vapor pressures between 0.1 and $10^{-7} \mathrm{~Pa}$ (Jimenez et al., 2009; O’Meara et al., 2014). In this range of vapor pressures individual compounds partition dynamically between the gas and particle phases, depending on total aerosol loading and temperature. Recently, highly oxidized organic compounds with even lower saturation vapor pressures (ELVOCs), which are essentially non-volatile, have also been detected both in laboratory studies and in the atmosphere (Ehn et al., 2012). These compounds are also produced primarily in the gas phase, and their saturation vapor pressures are needed to constrain their flux onto the atmospheric particulate phase. However, not all highly oxidized multifunctional compounds (HOMs) show extremely low saturation vapor pressures, and hence HOMs may still partition between gas and particle phase (Kurtén et al., 2016).

If we aim to predict atmospheric partitioning using a bottom-up approach using explicit or near-explicit models for gas phase oxidation of volatile organic compounds (VOCs), reliable model estimations of saturation vapor pressure for individual compounds are needed. Most estimation methods are constrained by databases heavily biased toward monofunctional compounds with saturation vapor pressures more in the range of $\sim 10^{3}-10^{5} \mathrm{~Pa}$ (Bilde et al., 2015). Experimental data of multifunctional compounds are required to improve estimation methods for atmospheric applications. However, even for the straight-chain dicarboxylic acids the experimental saturation vapor pressures reported in the literature deviate by up to four orders of magnitude between different measurement techniques (Bilde et al., 2015), and the difference can become as large as six orders of magnitude when additional functional groups are added to the straightchain dicarboxylic acids (Huisman et al., 2013). These differences are strikingly larger than the error estimates for the individual techniques, which are at most stated as a factor of 2. A very interesting observation of the Bilde et al. (2015) study when comparing different data sets was "... that the temperature dependence of the saturation vapor pressure, i.e., the slopes of the individual data sets (the enthalpies of sublimation and vaporization), agree almost always better with each other than the reported saturation vapor pressures themselves." Obviously, there are systematic biases of the different techniques, which are neither fully understood nor characterized.

Another important aspect of the differences observed between different data sets was identified to be caused by the physical state of the compound studied (Soonsin et al., 2010; Bilde et al., 2015). As multicomponent aerosol particles are expected often to be liquid or amorphous (glassy) under atmospheric conditions (Marcolli et al., 2004), the reference state for atmospheric applications is in general the subcooled liquid. If the vapor pressure is measured in the solid crystalline state, it needs to be converted to that of the subcooled liquid by taking the enthalpy of fusion and the change in molar heat capacity upon the crystalline solid-to-liquid transition into account (e.g., Bilde et al., 2015), introducing corresponding uncertainties. In addition, it is not always certain that a solid crystalline compound is purely crystalline without any amorphous content. Any amorphous material present can enhance the vapor pressure significantly (Soonsin et al., 2010), as the saturation vapor pressure over an amorphous solid resembles more that of the subcooled liquid than that of the crystalline solid. Therefore, a reference material for instrument testing should be preferable in liquid state at the temperatures at which the measurements are performed.

At present, there is no reference instrument nor technique which could serve as a "gold standard" for measuring the saturation vapor pressures of atmospheric multifunctional compounds. Without such a standard the lower limit of detection of a particular technique is difficult to access with reference materials available only with saturation vapor pressures above the targeted pressure range. Reference data of a homologous series could help to assess measurement techniques and instruments, and allow detection limits to be established. Internal consistency within a series increases its trustworthiness for establishing training sets needed for developing estimation methods.

Here, we use five different experimental setups based on three different techniques as well as high-temperature data reported in the literature to build such a reference data set. We determine saturation vapor pressures and enthalpies of vaporization for the homologous series of polyethylene glycols (PEGs; $\left.\mathrm{H}-\left(\mathrm{O}-\mathrm{CH}_{2}-\mathrm{CH}_{2}\right)_{n}-\mathrm{OH}\right)$ for $n=3$ to $n=8$ ranging in vapor pressure at $298 \mathrm{~K}$ from $10^{-7}$ to $5 \times 10^{-2} \mathrm{~Pa}$. Polyethylene glycols are chosen for four reasons: first, they are liquids at room temperature, so one of the potential sources of disagreement between different data sets identified by Bilde et al. (2015) is removed. Second, hightemperature saturation vapor pressures have been reported for some of the compounds in the literature and can be combined with our measurements performed at room temperature. Third, they span over a large range of saturation vapor pressures relevant for atmospheric applications. Fourth, PEGs contain ether and alcohol functional groups, which are both abundant in the organic fraction of atmospheric aerosols. Although we do not expect the presence of larger PEGs in the atmosphere, their functional groups nevertheless render them relevant for the atmosphere.

\section{Materials}

Polyethylene glycols with an oligomer purity of $>98 \%$ (penta- to octaethylene glycol from Polypure AS, Oslo, Norway) and an oligomer purity of $>98.5 \%$ (tri- and tetraethy- 
Table 1. Physical properties of the polyethylene glycols $\left(\mathrm{H}-\left(\mathrm{O}-\mathrm{CH}_{2}-\mathrm{CH}_{2}\right)_{\mathrm{n}}-\mathrm{OH}\right)$ used in this study: number, $n$; molar mass, $M$; melting temperature, $T_{\mathrm{m}}$; gas phase diffusivity in air, $D_{\mathrm{gas}}$, estimated as described in Bird et al. (2007) using $T_{\mathrm{c}}$ from UManSysProp (Topping et al., 2016); refractive index, $n_{\mathrm{D}}$; surface tension, $\sigma$. If not indicated otherwise, the data are from this study.

\begin{tabular}{|c|c|c|c|c|c|c|c|}
\hline & $n$ & $M\left[\mathrm{~g} \mathrm{~mol}^{-1}\right]$ & $T_{\mathrm{m}}[\mathrm{K}]$ & $\begin{array}{r}D_{\text {gas }}\left[\mathrm{m}^{2} \mathrm{~s}^{-1}\right] \\
\text { at } 25^{\circ} \mathrm{C}, 1013 \mathrm{hPa}\end{array}$ & $\begin{array}{r}n_{\mathrm{D}} \\
\text { at } 25^{\circ} \mathrm{C}\end{array}$ & $\begin{array}{r}\rho\left[\mathrm{g} \mathrm{cm}^{-3}\right] \\
\text { at } 25^{\circ} \mathrm{C}\end{array}$ & $\begin{array}{r}\sigma\left[\mathrm{mN} \mathrm{m}^{-1}\right] \\
\text { at } 25^{\circ} \mathrm{C}\end{array}$ \\
\hline Triethylene glycol & 3 & $150.2^{\mathrm{a}}$ & $266.0^{\mathrm{b}}$ & $\begin{array}{r}5.95 \times 10^{-6} \\
(5.90 \pm 0.059) \times 10^{-6 \mathrm{~d}}\end{array}$ & $1.4557^{\mathrm{c}}$ & $\begin{array}{r}1.108 \\
1.120^{\mathrm{e}}\end{array}$ & $45.15^{\mathrm{h}}$ \\
\hline Tetraethylene glycol & 4 & $194.2^{\mathrm{a}}$ & $267.6^{\mathrm{f}}$ & $5.20 \times 10^{-6}$ & $1.4593^{\mathrm{c}}$ & $\begin{array}{r}1.132 \\
1.120^{\mathrm{e}}\end{array}$ & $45.08^{h}$ \\
\hline Pentaethylene glycol & 5 & $238.4^{\mathrm{g}}$ & $270.3 \pm 1.0$ & $4.66 \times 10^{-6}$ & $\begin{array}{r}1.4592 \\
1.4617^{\mathrm{c}}\end{array}$ & $\begin{array}{r}1.155 \\
1.121^{\mathrm{e}}\end{array}$ & $44.95^{\mathrm{h}}$ \\
\hline Hexaethylene glycol & 6 & $282.3^{\mathrm{g}}$ & $281.2 \pm 1.0$ & $4.26 \times 10^{-6}$ & $\begin{array}{r}1.4623 \\
1.4637^{\mathrm{c}}\end{array}$ & $\begin{array}{r}1.180 \\
1.122^{\mathrm{e}}\end{array}$ & $44.87^{\mathrm{h}}$ \\
\hline Heptaethylene glycol & 7 & $326.4^{\mathrm{g}}$ & $289.2 \pm 1.0$ & $3.94 \times 10^{-6}$ & $\begin{array}{r}1.4636 \\
1.4653^{\mathrm{c}}\end{array}$ & 1.206 & $44.73^{\mathrm{h}}$ \\
\hline Octaethylene glycol & 8 & $370.4^{\mathrm{g}}$ & $297.4 \pm 1.0$ & $3.68 \times 10^{-6}$ & 1.4643 & 1.234 & \\
\hline
\end{tabular}

${ }^{a}$ Sigma-Aldrich. ${ }^{b}$ Curme and Johnston (1952). ${ }^{c}$ Gallaugher and Hibbert (1936) at $20^{\circ} \mathrm{C} .{ }^{d}$ Lugg (1968). ${ }^{e}$ Crespo et al. (2017). ${ }^{\text {f }}$ Oakwood Chemical. ${ }^{g}$ Polypure AS, Norway. ${ }^{\mathrm{h}}$ Gallaugher (1932).

lene glycol, Sigma-Aldrich) were used as received without any additional purification. Clearly, oligomer purity poses a potential problem for evaporation measurements: impurities of more volatile oligomers will lead to faster evaporation, while oligomers with lower volatility will bias toward lower evaporation. Samples of the same batch were shared for measurements with all five experimental systems. Melting points measured by differential scanning calorimetry and refractive indices measured with an Abbe-type refractometer are given in Table 1 as well as measured (Crespo et al., 2017) and estimated (Poling et al., 2001) densities. Also given are estimations for the gas phase diffusivity in air. Gas phase diffusivities of the organics are needed to calculate vapor pressures from measured evaporation rates by the electrodynamic balance (EDB) setups as well as those of the laminar flow tube-tandem differential mobility analyzer (FT-TDMA) setup. Since data are only available for triethylene glycol, diffusivities were estimated following Bird et al. (2007) and using $T_{\mathrm{c}}$ from UManSysProp (Topping et al., 2016). In addition, water activity measurements of a PEG400 mixture with mean molecular weight of $400 \mathrm{~g} \mathrm{~mol}^{-1}$ have been performed with a water activity meter (AquaLab, Model 3B, Decagon Devices, USA) to estimate PEG activities for aqueous PEG mixtures; see Fig. 1.

\section{Methods}

We used five experimental systems based on three different techniques to determine saturation vapor pressures. Detailed descriptions of the instruments have been published previously, but we provide brief descriptions here focusing on the uncertainties of vapor pressures derived in the following sections. Three systems use single micrometer-size

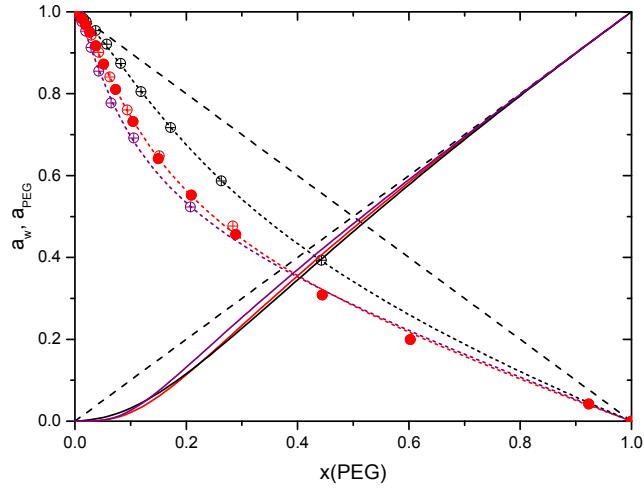

Figure 1. Water and PEG activities vs. mole fraction of PEG for PEGs with three different mean molar masses: PEG200 (black), PEG400 (red), and PEG600 (purple). Filled data points are from this study; open symbols from Ninni et al. (1999). The dashed, black lines illustrate ideal behavior, the short dashed lines are van Laar fits to the water activity data, and the solid lines are the PEG activities obtained from the van Laar fits using the Gibbs-Duhem relation.

particles levitated in an EDB to measure diffusion-controlled evaporation rates, namely the EDB setup at ETH Zurich (see Sect. 3.1), the EDB setup at Union College (see Sect. 3.2), and the EDB setup at the University of Bristol (see Sect. 3.3). Besides slightly different electrode configurations, the main difference of the EDB setups is the injection procedure, the accessible temperature range, and how the particles are sized during evaporation. For deducing vapor pressures from evaporation rates, all make use of Maxwell's quasi-stationary approximation (Maxwell, 1877) for evaporation of a motionless spherical particle relative to a uniform gaseous medium, 
with the particle's radius being large compared to the mean free path of the evaporating species, referred to as the continuum regime. The fourth setup, the Aarhus FT-TDMA instrument (see Sect. 3.4), uses a differential mobility analyzer (DMA) to select monodisperse particles in the accumulation mode size range and uses a Scanning Mobility Particle Sizer (SMPS) to measure the size distribution of the particles before and after partial evaporation in a laminar flow tube. A key parameter needed for quantitative analysis for the EDB experiments as well as the FT-TDMA setup is the diffusivity of the evaporating species in the gaseous medium. In the FTTDMA setup the particles' radii are of similar magnitude as the mean free path of the evaporating molecules (referred to as the transition regime). In this case, obtaining vapor pressures from measured evaporation rates requires knowledge of the mass accommodation coefficient (e.g., Bilde et al., 2015). The fifth instrument, the University of Manchester Knudsen effusion mass spectrometer (KEMS), measures the gas phase concentration of the vapor effusing from a macroscopic sample in a Knudsen cell using mass spectrometry; see Sect. 3.5. Here, it is assumed that the sample establishes an equilibrium within the cell.

In a Knudsen cell the mean free path is so large that mass transport can be described using kinetic gas theory, again with mass accommodation being a key parameter.

\subsection{EDB setup - ETH Zurich}

The electrodynamic balance setup at ETH Zurich uses a double-ring configuration (Davis et al., 1990) to levitate a charged particle in an environmental cell with a gas flow free of the evaporating species under investigation, but allowing precise conditioning of temperature and relative humidity (Zardini et al., 2006; Soonsin et al., 2010; Huisman et al., 2013). Evaporation rates are measured at fixed temperature and relative humidity using optical resonance spectroscopy in backscattering geometry with a broadband LED source and applying Mie theory for the analysis (Zardini et al., 2006). The accuracy of the rate measurement is estimated to be $\pm 1 \times 10^{-6} \mu \mathrm{m}^{2} \mathrm{~s}^{-1}$. Huisman et al. (2013) did a detailed error analysis for the setup and evaluation scheme for determining vapor pressures from the measured evaporation rates and concluded that the largest systematic uncertainty arises from estimating the gas phase diffusivity ( $\pm 20 \%$ uncertainty in vapor pressure), while possible drifts in relative humidity could lead to some error $(2 \%)$ when measuring at higher humidity. Obviously, the uncertainty associated with a measurement depends also on the total time span observing the evaporation. Previously, we estimated the lower limit of quantification for our setup to be about $4 \times 10^{-7} \mathrm{~Pa}$ for a $24 \mathrm{~h}$ measurement period. Conservatively, we estimated the uncertainty for each individual measurement to be $\pm 35 \%$ plus the lower limit of quantification based on the total time spent to measure the rate. To avoid being biased by impurities of higher volatility, measurements were started typically $6 \mathrm{~h}$ after injecting the particle in the EDB.

\subsection{EDB setup - Union College, Schenectady}

The electrodynamic balance at Union College uses a doublering configuration similar to that of the ETH Zurich unit. Temperature and relative humidity are monitored via a precision PT100 temperature sensor (Omega PRTF-10-3-1001/4-3/4-E) integrated into the chamber and a chilled-mirror dew point hygrometer (General Eastern OptiSonde-1-1-52-2-1-A-0) immediately after the chamber. All gas transfer lines are heated to at least $33^{\circ} \mathrm{C}$ but no more than $45^{\circ} \mathrm{C}$ to prevent condensation of water vapor. Evaporation rates are measured at fixed temperature and relative humidity by optical resonance spectroscopy using a broadband $\operatorname{LED}(\lambda=$ $850 \pm 20 \mathrm{~nm}$ ) at a $90^{\circ}$ scattering angle, applying Mie theory for the analysis following Zardini et al. (2006). Propagation of error was used to estimate uncertainty in the calculated vapor pressures, estimated uncertainty in temperature is set as $0.25 \mathrm{~K}$, estimated uncertainty in humidity is conservatively set at $2 \%$, and uncertainty in density and diffusivity are set at $20 \%$. The estimated uncertainty that results is driven almost entirely by the uncertainty in RH, except at low RH (e.g., $<25 \%$ ), when all other terms contribute approximately equally.

\subsection{EDB setup - University of Bristol}

The EDB instrument has been described extensively in previous publications (Davies et al., 2012, 2013; Rovelli et al., 2016). EDB measurements at the University of Bristol were performed with a charged droplet confined between two cylindrical electrodes, in a temperature- and relative humidity- controlled (248-330 K, RH of 0 to $>90 \%$, respectively) chamber. In these measurements, the organic droplet was always trapped in a dry flow of nitrogen gas (assuming an $\mathrm{RH}$ equal to $0 \%$ ). The organic evaporating droplet was illuminated with a $532 \mathrm{~nm}$ laser and the evaporation profile determined from the detected phase function using the geometric optics approximation $( \pm 100 \mathrm{~nm})$ (Glatschnig and Chen, 1981). Several evaporating droplets were collected to ensure measurement reproducibility, with a minimum of five droplets collected for each PEG compound at each temperature. The derived vapor pressure is an average of all measurements taken, which have very good reproducibility. The error associated with this measurement therefore corresponds to the error estimated for the diffusion constant used in the determination of vapor pressure $(20 \%)$. At the temperatures studied here, the uncertainty in temperature is smaller than the size of the points shown, increasing from $1^{\circ} \mathrm{C}$ at $15^{\circ} \mathrm{C}$ to $2{ }^{\circ} \mathrm{C}$ at $40{ }^{\circ} \mathrm{C}$. 


\subsection{FT-TDMA setup - University of Aarhus}

ARAGORN (AaRhus Aerosol Gas evapORatioN flow tube) is a TDMA setup including a laminar flow tube (Bilde et al., 2003; Emanuelsson et al., 2016) allowing for studies under dry (e.g., Bilde et al., 2003; Frosch et al., 2010) or humid (e.g., Riipinen et al., 2006; Zardini et al., 2010) conditions. In this work dried aerosol particles from nebulized aqueous solution were size-selected to monodisperse size distributions $(69-285 \mathrm{~nm})$ using a differential mobility analyzer (DMA), diluted with dry clean air, and allowed to evaporate in a temperature-controlled $(282-322 \mathrm{~K})$ laminar flow tube at ambient pressure. The peaks remained monodisperse during evaporation, and the initial and final peak sizes (typically after $40 \mathrm{~s}$ of evaporation) were measured using a SMPS consisting of a DMA (Hauke Vienna short type, negative power supply, FuG HCE) connected to a condensation particle counter (CPC TSI 3776). Saturation vapor pressures for PEG5, PEG6, and PEG7 were derived from experimental data as described in Bilde et al. (2003), using a mass accommodation coefficient equal to 1 , gas phase diffusivities reported in Table 1, and subcooled liquid densities at the corresponding temperature using Poling et al. (2001). For the analysis of the FT-TDMA data, surface tensions are needed to take into account the Kelvin effect. As precise surface tension data are available (Gallaugher and Hibbert, 1937; Gallaugher, 1932) (see Table 1), we use those for the analysis of the FT-TDMA experiments. (Since they are approximately the same for PEG5 to PEG7 - within 5\%o - we used the one for PEG7 in our calculations.) The relative uncertainty on the individually measured saturation vapor pressures is estimated to be around $50 \%$ (Bilde et al., 2003).

\subsection{KEMS setup - University of Manchester}

The Knudsen effusion mass spectrometer has been previously described in multiple publications (e.g., Booth et al., 2009). Errors for solid-state measurements with the KEMS have previously been determined by calculating the standard deviation of measured species using different reference samples. For example Booth et al. (2009) used three different reference compounds to calculate the error for oxalic acid. Based on the numerous repeat runs presented in Booth et al. (2010) over a range of $20 \mathrm{~K}$, a maximum error of $\pm 40 \%$ was determined in the solid state. Deriving the subcooled liquid pressure from solid-state vapor pressure measurements increased the error to a maximum of $\pm 75 \%$ and is representative of all previously published measurements on solid samples. The maximum uncertainty associated with the PEG series is estimated to be $\pm 40 \%$, as the sample is measured in the liquid state where no subcooled liquid correction is required. Additional uncertainties are expected to increase this general error as we approach the lower limit of the instrument. In these regions, the mass spectrometry technique will result in decreased signal-to-noise ratios, introducing a higher error into the measurements. It is also possible that impurities in the sample and the provenance of sample preparation and storage would have an increasing impact on error as the vapor pressure decreases. Random errors are possible as a result of the variation in sensitivity of the mass spectrometer (ionizer and/or detector). This factor is limited by ensuring that the instrumental background signal is consistent between both the reference samples and the PEGs. We therefore feel that this random effect will cause very little error in final results. Systematic errors can be introduced by the choice of reference compounds as measurements, in all cases, are relative to this choice and from calculation of the ionization cross section. For all measurements the accommodation coefficient is assumed to be identical between reference samples and the PEGs. Such an assumption may introduce unquantifiable errors, but it is expected that they are minimized by the appropriate choice of similar reference and sample compounds (e.g., Booth et al., 2012). These sources of uncertainty require further elucidation with an extended set of compounds. For this study, based on the standard deviation of 4 runs of PEG 7 an associated error of $\pm 29 \%$ is initially calculated, yet we prescribe a value of $\pm 40 \%$ based on the aforementioned issues.

\subsection{Quantum chemistry calculations}

Saturation vapor pressures were calculated for the the PEG series with $n=1-5$ using multiple low-energy conformers. All conformers were first obtained with the Merck molecular force field (MMFF) and B3LYP density functional (Becke, 1993a, b) using the Spartan '14 program (Wavefunction Inc., 2014). For PEGs with $n=1-3$ we performed systematic conformer sampling using the MMFF in order to produce a representative set of unique conformers. We selected all conformers of PEG1 and PEG2 and the conformers within $5 \mathrm{kcal} \mathrm{mol}^{-1}$ of the lowest-energy MMFF conformer of PEG3 and optimized these using the B3LYP/6-31+G(d) level of theory (Hehre et al., 1972). For PEG4 we performed full Monte Carlo sampling using the MMFF, finding over 50000 conformers. We selected the conformers within $5 \mathrm{kcalmol}^{-1}$ of the lowest-energy MMFF conformer and computed the B3LYP/6-31+G(d) single-point energies of these structures. Next, we optimized the 100 lowest-energy B3LYP/6-31+G(d) conformations at the same level of theory. Due to the large number of different conformers for PEG5, we set the maximum number of conformers to 100000 and performed Monte Carlo sampling using the MMFF. Then we selected the 100 lowest-energy MMFF conformers and optimized the structures at the B3LYP/6-31+G(d) level of theory. The lowestenergy conformers were used in gas phase and COSMORS (COnductor-like Screening Model for Real Solvents) calculations with BP_TZVP_C30_1701 (BP/TZVP) (Schäfer et al., 1994) parametrization using TmoleX version 4.2 (Steffen et al., 2010) and TURBOMOLE version 7.1 (TURBO- 
MOLE, 2016). The BP/TZVP refers to a B88-VWN-P86 functional with a resolution-of-the-identity (RI) approximation together with the TZVP basis set and corresponding auxiliary basis set for the RI computation. Calculations yielded the COSMO-RS and energy files which were used as an input for COSMOtherm (COSMOtherm, 2017; Eckert et al., 2002) saturation vapor pressure calculations.

\section{Results and discussion}

Figures 2 through 7 show the pure compound saturation vapor pressures as a function of inverse temperature for each polyethylene glycol measured with the experimental systems described above together with available literature data; all numerical values are provided in Krieger (2017). The vapor pressures measured with our setups cover a range from 1 to $10^{-8} \mathrm{~Pa}$, with literature data extending this range to pressures up to $10^{4} \mathrm{~Pa}$. Only pentaethylene glycol could be measured with all three techniques; some instruments were not able to measure the glycols with high saturation vapor pressures because of fast evaporation, while other instruments reached their lower limit of detection for glycols with larger molecular weight and low saturation vapor pressure.

Triethylene glycol was measured with the three EDB setups, as shown in Fig. 2a and b for a cut-out to show our data in more detail. The setup at the University of Bristol allows measurements at elevated temperatures, which agree very well with extrapolated high-temperature literature data. While the Union College EDBs show slightly larger saturation pressures, the agreement with the Bristol EDB data is within error for almost all data points. The setup at ETH Zurich requires a time span of about 30 min to establish constant conditions of temperature and relative humidity after injecting a particle, which limits its ability to measure fast evaporation rates. Hence, the measurements for PEG3 were performed at temperatures below room temperature and at relative humidities ranging from almost $0 \%$ at the lowest temperatures to $94 \%$ relative humidity at $288 \mathrm{~K}$. As discussed in Sect. 3.1, measurements at elevated relative humidity increase the uncertainty in differentiating between evaporation and shrinkage due to drifts in humidity, which has been taken into account by a factor-of- 2 increase in estimated uncertainty. However, while the data taken at $288 \mathrm{~K}$ agree with the other two EDB data, the lower-temperature data are clearly below those of the other two EDBs. The bias could arise from higher mass oligomeric impurities in the sample, since the measurements at lower temperatures required a considerably longer time to reach equilibrium with respect to temperature and humidity, during which a large volume of the particle already evaporated with corresponding potential enrichment of such impurities.

Jakubczyk et al. (2010) used an EDB setup as well, and their saturation vapor pressures measured at $298 \mathrm{~K}$ compares very favorably with the EDB data of the University of Bristol
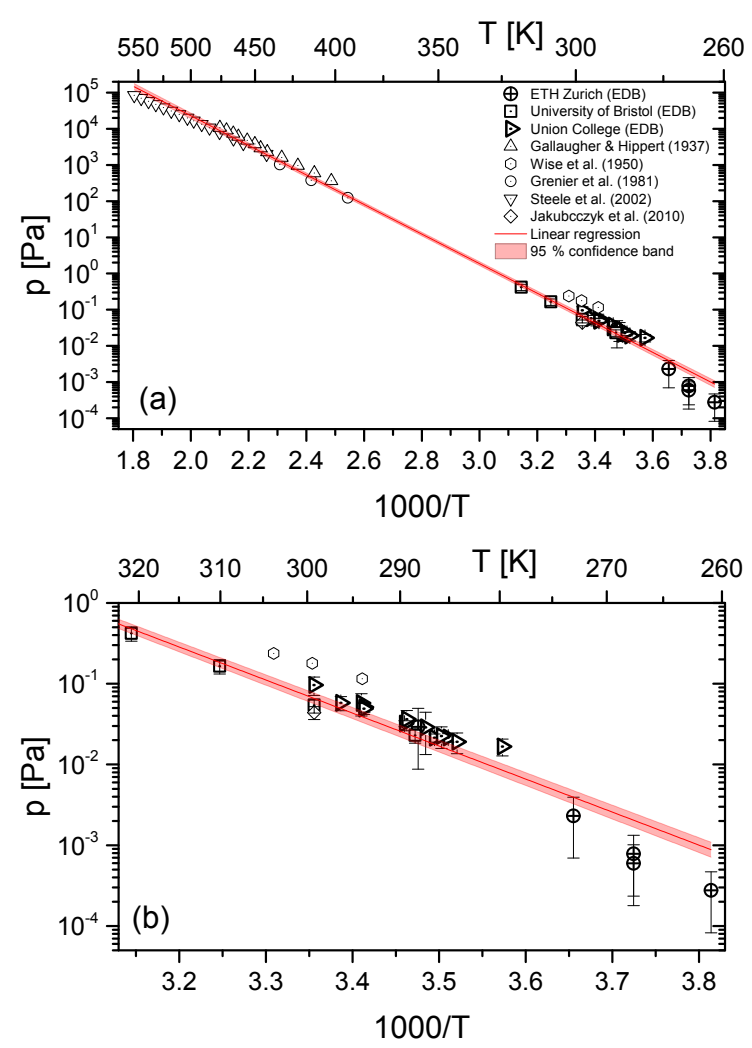

Figure 2. Saturation vapor pressures vs. temperature of triethylene glycol (PEG3). Bold open symbols: this work; open symbols: data reported in the literature. Red line: linear regression to all data below $500 \mathrm{~K}$; red shaded area: $95 \%$ confidence band of the regression. (a) Overview of all data, (b) cut-out showing the pressure range of the experimental data of this study.

measurement at this temperature. There is one more data set at lower temperatures available (Wise et al., 1950), obtained by observing the formation of condensates of the vapor on a polished mirror. These data seem to significantly overestimate the vapor pressure and were discarded for the following evaluations. In addition, Grenier et al. (1981) have measured gas saturation in an inert carrier gas, and Steele et al. (2002), using an ebulliometric technique, have measured the saturation vapor pressure at much higher temperatures from about 400 up to $500 \mathrm{~K}$.

The data at the highest and lowest temperatures seem to deviate from a Clausius-Clayperon temperature dependence, assuming the enthalpy of evaporation to be independent of temperature. Nevertheless, we included a part of these data when performing a linear regression using the data between 260 and $500 \mathrm{~K}$, yielding a saturation vapor pressure, $p^{0}$, of $\left(6.68_{-0.95}^{+1.10}\right) \times 10^{-2} \mathrm{~Pa}$ at $298.15 \mathrm{~K}$ and an enthalpy of evaporation, $\Delta H_{\mathrm{vap}}$, of $84.3 \pm 1.9 \mathrm{~kJ} \mathrm{~mol}^{-1}$ at this temperature; see Table 2 . Here the error marks the $95 \%$ confidence interval of the regression. 
Table 2. Saturation vapor pressures at $298.15 \mathrm{~K}$ and enthalpies of vaporization of the polyethylene glycols measured in this study as well as estimated enthalpies of vaporization at $T^{\ominus}=298.15 \mathrm{~K}$, together with the results of the quantum chemistry calculations. In addition we provide experimental data from the literature for ethylene glycol and diethylene glycol.

\begin{tabular}{|c|c|c|c|c|c|c|c|}
\hline & $n$ & $\begin{array}{r}p(\exp ) \\
{[\mathrm{Pa}]}\end{array}$ & $\begin{array}{r}\Delta H_{\text {vap }}(\exp , \bar{T}) \\
{\left[\mathrm{kJ} \mathrm{mol}^{-1}\right]}\end{array}$ & $\begin{array}{c}\bar{T} \\
{[\mathrm{~K}]}\end{array}$ & $\begin{array}{r}\Delta H_{\text {vap }}(\exp , 298 \mathrm{~K}) \\
{\left[\mathrm{kJ} \mathrm{mol}^{-1}\right]}\end{array}$ & $\begin{array}{r}p(\text { calc }) \\
{[\mathrm{Pa}]}\end{array}$ & $\begin{array}{r}\Delta H_{\text {vap }}(\text { calc, } 298 \mathrm{~K}) \\
{\left[\mathrm{kJ} \mathrm{mol}^{-1}\right]}\end{array}$ \\
\hline Triethylene glycol & 3 & $\left(6.68_{-0.95}^{+1.10}\right) \times 10^{-2}$ & $78.3 \pm 0.7$ & 349 & $84.3 \pm 1.9$ & $2.65 \times 10^{0}$ & 68.81 \\
\hline Tetraethylene glycol & 4 & $\left(1.69_{-0.10}^{+0.11}\right) \times 10^{-2}$ & $77.1 \pm 0.4$ & 345 & $82.1 \pm 1.6$ & $1.82 \times 10^{-1}$ & 72.78 \\
\hline Pentaethylene glycol & 5 & $\left(5.38_{-0.63}^{+0.71}\right) \times 10^{-4}$ & $90.6 \pm 1.1$ & 339 & $94.6 \pm 1.6$ & $2.10 \times 10^{-2}$ & 81.60 \\
\hline Hexaethylene glycol & 6 & $\left(3.15_{-0.49}^{+0.58}\right) \times 10^{-5}$ & $102.1 \pm 1.5$ & 351 & $107.2 \pm 2.1$ & - & - \\
\hline Heptaethylene glycol & 7 & $\left(1.38_{-0.35}^{+0.47}\right) \times 10^{-6}$ & $113.7 \pm 2.7$ & 357 & $119.2 \pm 3.2$ & - & - \\
\hline Octaethylene glycol & 8 & $\left(9.2_{-6.4}^{+20.4}\right) \times 10^{-8}$ & $124.2 \pm 9.7$ & 363 & $130.2 \pm 9.9$ & - & - \\
\hline Ethylene glycol & 1 & $11.7 \pm 0.6^{\mathrm{a}}$ & - & - & $65.6 \pm 0.3^{\mathrm{b}}$ & $3.98 \times 10^{1}$ & 60.75 \\
\hline Diethylene glycol & 2 & $0.6 \pm 0.03^{\mathrm{a}}$ & $66.9 \pm 0.3^{b}$ & 420 & $80.2 \pm 4.0^{\mathrm{b}}$ & $3.80 \times 10^{0}$ & 67.41 \\
\hline
\end{tabular}

${ }^{a}$ Ambrose and Hall (1981). ${ }^{\text {b }}$ Chickos and Acree Jr. (2003).
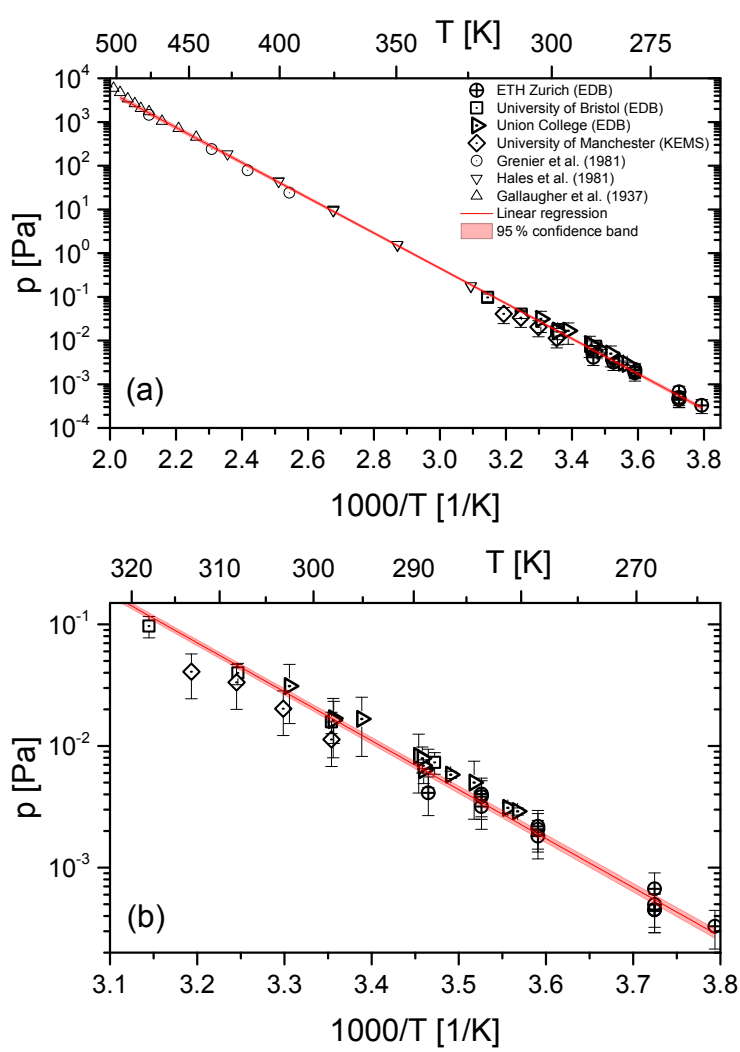

Figure 3. Saturation vapor pressures vs. temperature of tetraethylene glycol (PEG4). Bold open symbols: this work; open symbols: data reported in the literature. Red line: linear regression of all data below $495 \mathrm{~K}$. (a) Overview of all data, (b) cut-out showing the pressure range of the experimental data of this study.

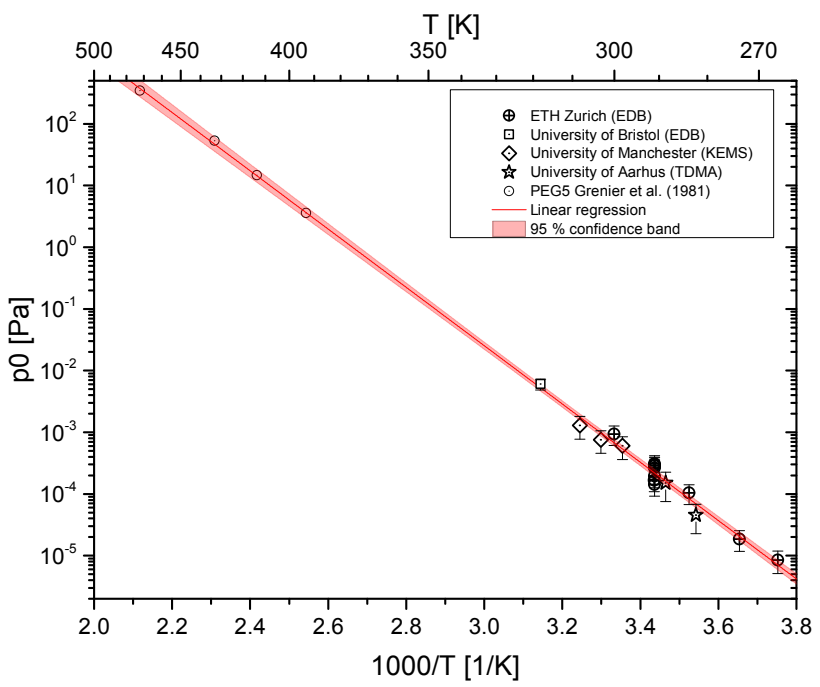

Figure 4. Saturation vapor pressures vs. temperature of pentaethylene glycol (PEG5). Symbols as in Fig. 2.

Tetraethylene glycol was measured with the three EDB setups and the KEMS, as shown in Fig. 3. These measurements cover a temperature range from 263 to $318 \mathrm{~K}$; together with data available in the literature at higher temperatures, the complete data set covers a range from 263 to $482 \mathrm{~K}$. All data fit well to a temperature-independent ClausiusClapeyron relationship, yielding a saturation vapor pressure, $p^{0}$, of $\left(1.69_{-0.10}^{+0.11}\right) \times 10^{-2} \mathrm{~Pa}$ at $298.15 \mathrm{~K}$ and an enthalpy of evaporation, $\Delta H_{\text {vap }}(298 \mathrm{~K})$, of $82.1 \pm 1.6 \mathrm{~kJ} \mathrm{~mol}^{-1}$. Figure $3 \mathrm{~b}$ shows a cut-out of Fig. 3a to allow closer inspection of the data measured with our setups. 


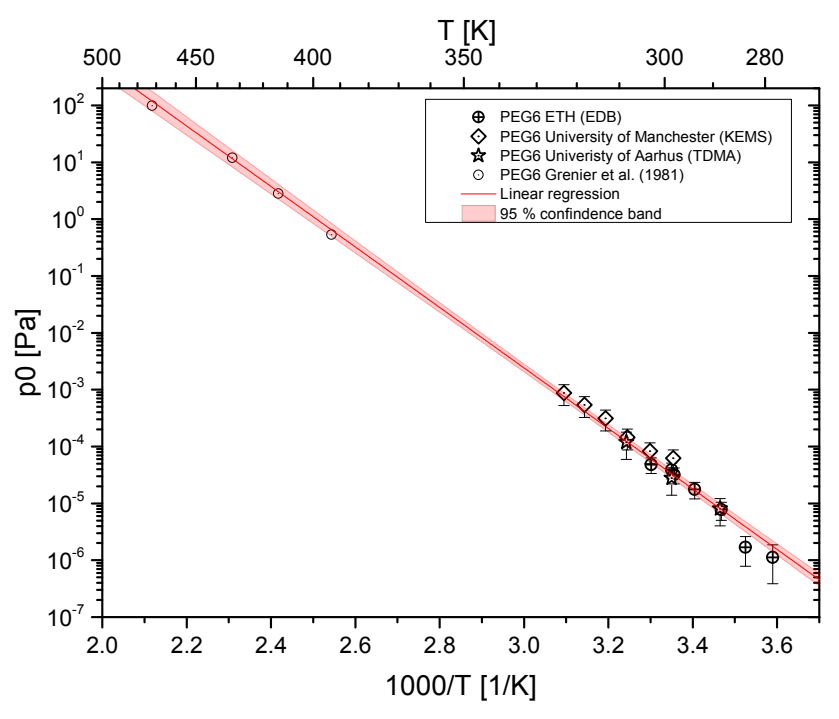

Figure 5. Saturation vapor pressures vs. temperature of hexaethylene glycol (PEG6). Symbols as in Fig. 2.

Pentaethylene glycol could be measured with all three techniques used in this study, as shown in Fig. 4. Again, our data cover a considerable temperature range of over $50 \mathrm{~K}$ : from 266 to $318 \mathrm{~K}$. The vapor pressure measured over this temperature range increases from $10^{-5}$ to $10^{-2} \mathrm{~Pa}$. A number of measurements performed with the EDB setup of ETH Zurich at elevated relative humidities ranging from dry (less than $3 \%$ ) to $50 \% \mathrm{RH}$ at a temperature of $291 \mathrm{~K}$ show that the scatter in the deduced pure component vapor pressure increases when measuring at elevated humidities. The data differ by up to a factor of 2 , which is beyond the estimated error of $\pm 35 \%$. Of course, when measuring a binary mixture of PEG and water, the activity of the PEG at the relative humidity of the measurement is needed to evaluate the vapor pressure from evaporation rates (Krieger et al., 2012). Since the water activities for polymeric mixtures with mean molecular weights of $200 \mathrm{~g} \mathrm{~mol}^{-1}$ (PEG200), $400 \mathrm{~g} \mathrm{~mol}^{-1}$ (PEG400), and $600 \mathrm{~g} \mathrm{~mol}^{-1}$ (PEG600) have been extensively measured (see Fig. 1), we are able to constrain the activity of the PEG in this mass range to better than $20 \%$. In particular at relative humidities lower than $30 \%$ the binary system is close to ideal behavior, which further reduces any potential error in the activity estimate. Also, there is no systematic trend in vapor pressure with water content of the particle. Hence it is unlikely that the scatter is due to the uncertainty in activity. Rather, there exist other systematic errors when measuring at elevated humidities which are not yet identified.

A linear regression for all pentaethylene data, including the high-temperature data of Grenier et al. (1981), yields a saturation vapor pressure, $p^{0}$, of $\left(5.38_{-0.63}^{+0.71}\right) \times 10^{-4} \mathrm{~Pa}$ at $298.15 \mathrm{~K}$ and an enthalpy of evaporation, $\Delta H_{\mathrm{vap}}(298 \mathrm{~K})$, of $94.6 \pm 1.6 \mathrm{~kJ} \mathrm{~mol}^{-1}$.

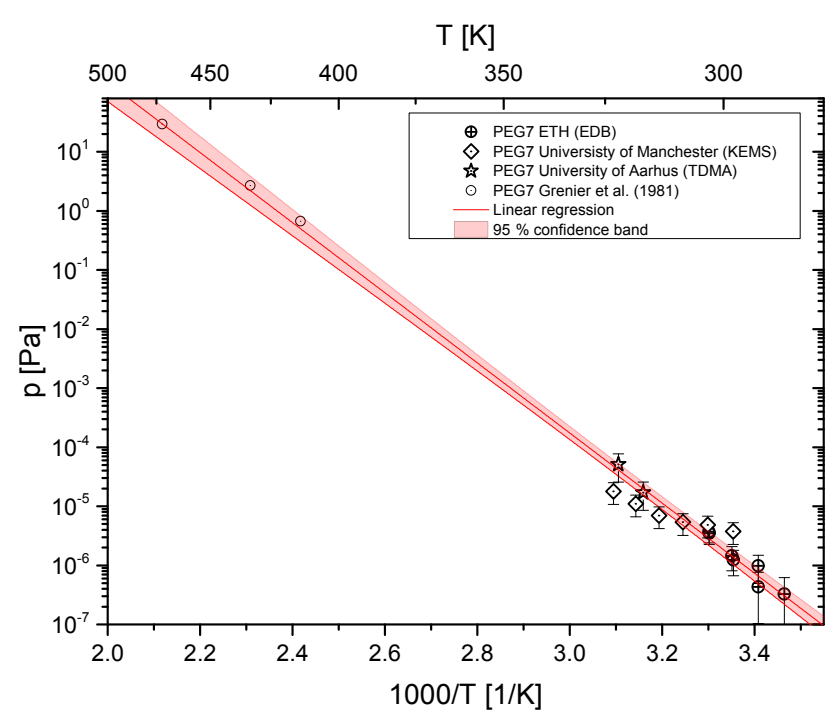

Figure 6. Saturation vapor pressures vs. temperature of heptaethylene glycol (PEG7). Symbols as in Fig. 2.

Hexaethylene glycol was measured with the EDB Zurich setup, the Manchester KEMS, and the FT-TDMA setup of the University of Aarhus, as shown in Fig. 5. Vapor pressures were measured over a temperature range of $45 \mathrm{~K}$ covering a range in pressures from $10^{-6}$ to $10^{-3} \mathrm{~Pa}$. All data agree within error, but there appears to be a slightly different temperature trend in the KEMS data and the EDB data. The linear regression for all data, including the hightemperature data of Grenier et al. (1981), yields a saturation vapor pressure, $p^{0}$, of $\left(3.15_{-0.49}^{+0.58}\right) \times 10^{-5} \mathrm{~Pa}$ at $298.15 \mathrm{~K}$ and an enthalpy of evaporation, $\Delta H_{\text {vap }}(298 \mathrm{~K})$, of $107.2 \pm 2.1$ $\mathrm{kJ} \mathrm{mol}^{-1}$.

Again, heptaethylene glycol could be measured with the EDB Zurich setup, the Manchester KEMS, and the FTTDMA setup of the University of Aarhus, as shown in Fig. 6. The deviation in temperature trends between the three different measurement setups becomes more apparent at the lower vapor pressures of this compound at about room temperature. Nevertheless, all data seem to be consistent with the $95 \%$ confidence interval of a linear regression to all data plus the high-temperature data of Grenier et al. (1981). The regression yielded a saturation vapor pressure, $p^{0}$, of $\left(1.38_{-0.35}^{+0.47}\right) \times 10^{-6} \mathrm{~Pa}$ at $298.15 \mathrm{~K}$ and an enthalpy of evaporation, $\Delta H_{\mathrm{vap}}(298 \mathrm{~K})$, of $119.2 \pm 2.7 \mathrm{~kJ} \mathrm{~mol}^{-1}$. Note that a correct temperature trend is crucial for extrapolations to lower temperatures when measuring above room temperature for atmospheric applications. Clearly, relying on one of our data sets alone would yield unrealistic values for the enthalpy of evaporation.

The highest-molecular-weight compound in the homologous series of PEGs for which a saturation vapor pressure at about ambient temperatures could be measured with our 


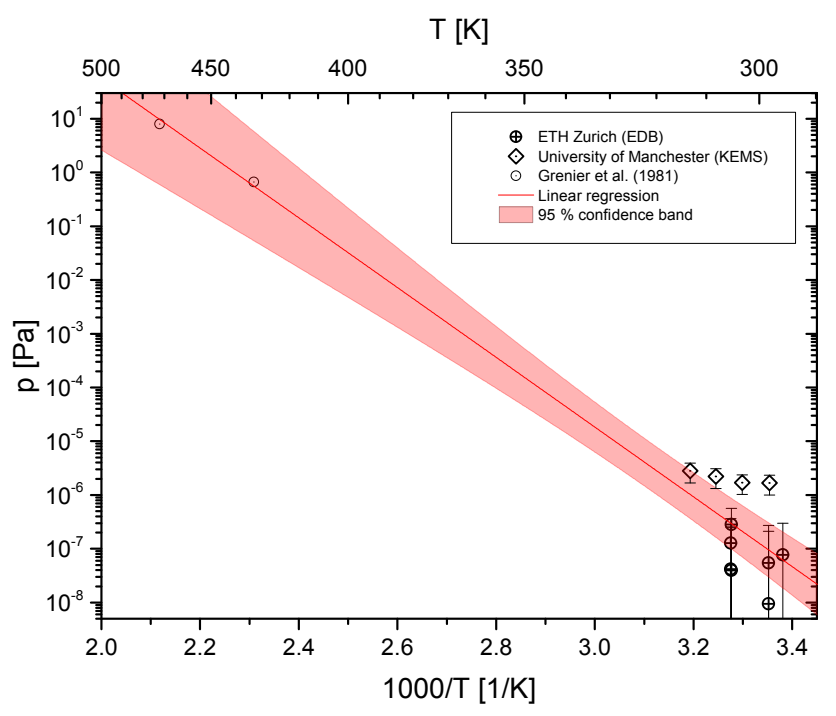

Figure 7. Saturation vapor pressures vs. temperature of octaethylene glycol (PEG8). Symbols as in Fig. 2.

techniques was octaethylene glycol. Both the KEMS instrument and the EDB Zurich instrument were used to determine vapor pressures with temperatures ranging from 296 to $313 \mathrm{~K}$. The vapor pressure at these temperatures ranges from less than $10^{-7}$ to about $10^{-6} \mathrm{~Pa}$. The EDB data scatter over 1 order of magnitude and are about 1 order of magnitude smaller than those measured using the KEMS instrument. While the KEMS data do not show scatter, they show almost no temperature dependence, which may indicate that the lower limit of detection is reached at these vapor pressures. Again we did a linear regression including the high-temperature data of Grenier et al. (1981), resulting in a saturation vapor pressure, $p^{0}$, of $\left(9.2_{-6.4}^{+20.4}\right) \times 10^{-8} \mathrm{~Pa}$ at $298.15 \mathrm{~K}$ and an enthalpy of evaporation, $\Delta H_{\mathrm{vap}}(298 \mathrm{~K})$, of $130.2 \pm 9.9 \mathrm{~kJ} \mathrm{~mol}^{-1}$.

A summary of the derived saturation vapor pressures and enthalpies of vaporization is given in Table 2 .

When looking at all data, it is evident that the hightemperature literature data agree quite well with our data at about room temperature. Hence, extrapolation of experiments performed at elevated temperatures toward atmospheric temperatures is possible with high accuracy as long as the temperature trend is measured accurately enough. More quantitatively, extrapolation of the high-temperature literature data to $298.15 \mathrm{~K}$ incorporating the temperature dependence of the enthalpy of vaporization as detailed in Appendix B (orange filled circles in Fig. 8) yields values that agree well within error with the newly derived saturation vapor pressures for PEG3, PEG7, and PEG8 of this study and agree better than within a factor of 2 for PEG4, PEG5, and PEG6. In contrast, using a constant enthalpy of vaporization for the extrapolation yields very good agreement for PEG4, PEG5, and PEG6 but substantial deviation - up to a factor of

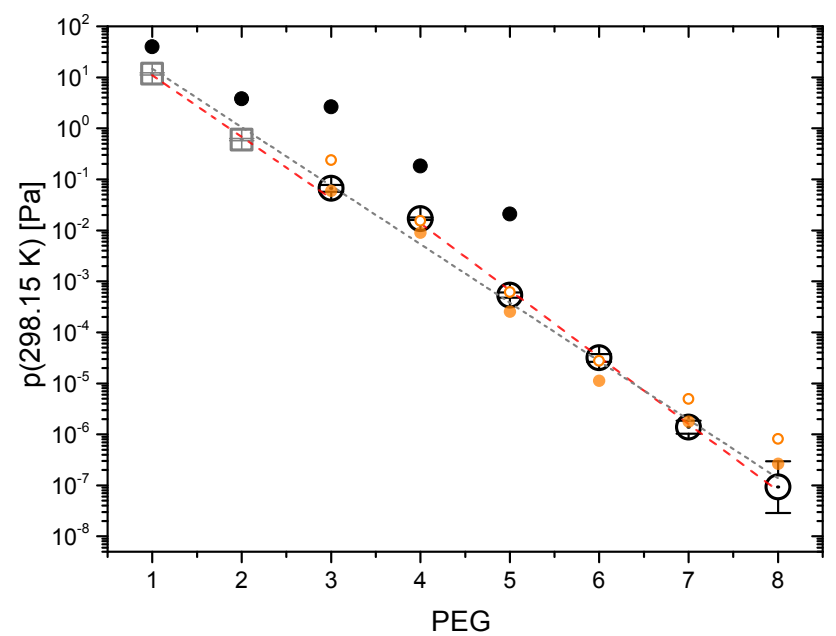

Figure 8. Saturation vapor pressure at $298.15 \mathrm{~K}$ plotted for all PEGs. Open black circles with error bars: results of this study. Filled orange circles: extrapolation of high-temperature literature data to $298.15 \mathrm{~K}$ using an estimation of the temperature dependence of the enthalpy of evaporation as detailed in Appendix B. Open orange circles: extrapolation of high-temperature literature data to $298.15 \mathrm{~K}$ assuming a constant enthalpy of evaporation. Filled black circles: computational predictions from this study. Open squares with error bars: Ambrose and Hall (1981). Dashed gray line is a linear regression to all the experimental data; dashed red lines are separate linear regressions for $n=1$ to $n=3$ and $n=4$ to $n=8$.

10 - for PEG3, PEG7, and PEG8. We conclude that extrapolation to lower temperatures of high-temperature data should take the temperature dependence of the enthalpy of vaporization (Kirchhoff's law) into account. Also, it helps tremendously when data cover a large temperature range. It is obvious that each technique used in our study has an optimal pressure range for obtaining high-quality data. The optimal pressure range should be utilized in the future by rather performing measurements at elevated temperatures with extrapolation to atmospheric temperatures and avoiding pressure ranges where the accuracy of the derived saturation vapor pressures is limited.

In addition, the good agreement between the FT-TDMA data and all other techniques points towards the accommodation coefficient being close to 1 as this was assumed for the data analysis. To retrieve a lower limit for the accommodation coefficient, we analyzed the FT-TDMA experiments, varying the accommodation coefficient until the calculated vapor pressure including its error exceeded the reference pressure confidence interval given in Table 2 at the temperature of each FT-DMA experiment. The mean value of these accommodation coefficients for all experiments is equal to 0.5 , and there is no discernible difference between the experiments for different PEGs. We conclude that the mass accommodation coefficient of the PEGs based on our study is greater than 0.5 . 


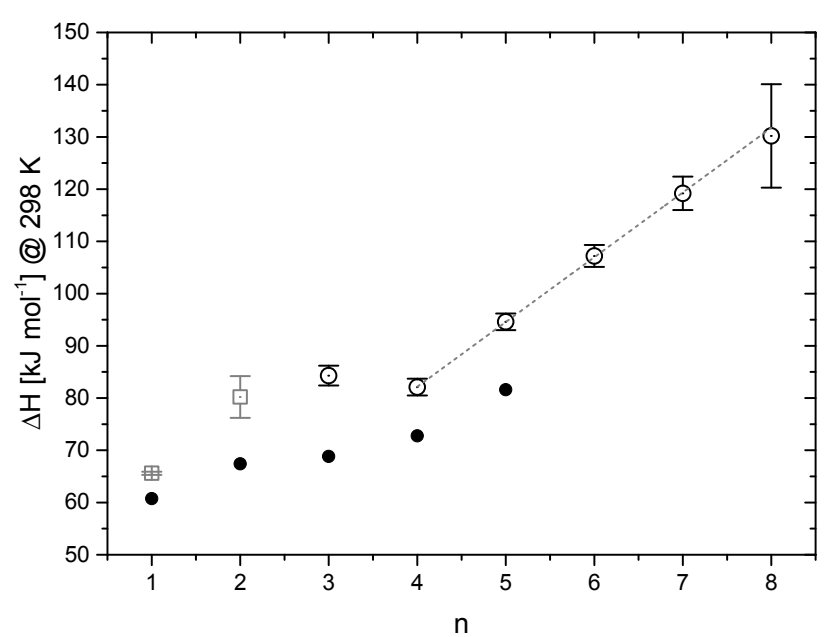

Figure 9. Enthalpies for all PEGs. Open circles: this study; open squares: Chickos and Acree Jr. (2003). Filled circles: computational predictions from this study. Dashed line is a fit through the data of PEG4 to PEG8.

In Fig. 8 we plot the saturation vapor pressures on a logarithmic scale at $298.15 \mathrm{~K}$ vs. the number of PEG units. The saturation pressures show an exponential dependence on the number of PEG units with a reduction in pressure by a factor of 13.8 per PEG unit added, as indicated by the linear regression (dashed gray line) over the complete range of PEGs in the figure. Closer inspection reveals that there is a change in slope between PEG3 and PEG4. In particular the tetraethylene glycol deviates from the linear relationship by a factor of 3 to higher pressures, out of the $95 \%$ confidence interval uncertainty of the derived vapor pressures. As the measurements of this compound are particularly well constrained by numerous data not only from this study (see Fig. 3), we conclude that this deviation is real. Since there is no fundamental reason for the homologous series to follow a strict exponential behavior, it is of interest whether computational prediction methods are able to reproduce this behavior. In Fig. 8 we also plot the results of the COSMOtherm calculations given in Table 2. Clearly, these calculations overpredict the vapor pressure by a factor of 3-40. Interestingly, they show a similar deviation from the linear trend to the experimental data, but here the change in slope occurs at 1 PEG unit lower than what is observed in the experimental data.

Separate linear regressions for ethylene glycol to PEG3 and for PEG4 to PEG8 yield regression lines within the $95 \%$ confidence interval of the individual data for each PEG (red dashed lines in Fig. 8). Hence, we predict a saturation vapor pressure for nonaethylene glycol with some confidence as $\left(3.7_{-2.0}^{+4.1}\right) \times 10^{-9} \mathrm{~Pa}$ at $298.15 \mathrm{~K}$. All our instruments were not able to measure a vapor pressure that low.
In the plot of the enthalpies at $298.15 \mathrm{~K}$ for the homologous series in Fig. 9 there is a general trend for an increase in enthalpy of vaporization with the number of PEG units, but a strict linear dependence is observed only from PEG4 to higher PEGs, with an average $12.3 \mathrm{~kJ} \mathrm{~mol}^{-1}$ increase per PEG unit. The lower-molecular-weight PEGs show a more irregular behavior, while the COSMOtherm calculations reveal again a change in slope between diethylene glycol and PEG4, while the increase for ethylene glycol to diethylene glycol and from PEG4 to PEG5 is similar. Again, this may be an indication that there is a transition occurring in the homologous series at triethylene glycol. Note that the transition does not need to be related to changes in the condensed phase but might also be related to the gas phase, e.g., internal hydrogen bonds that stabilize larger oligomers.

\section{Conclusions}

A reference data set for validating vapor pressure measurement techniques is provided, spanning a range in pressure at room temperature from $5 \times 10^{-2}$ to $10^{-7} \mathrm{~Pa}$ based on experimental data and extending to $10^{-9} \mathrm{~Pa}$ with high confidence based on the observed trend in the homologous series of polyethylene glycols. Our data reveal clearly that (at least for the compounds studied) extrapolations to lower temperatures are possible as long as the temperature dependence is correctly measured. Therefore, it seems to be more appropriate to perform measurements at (slightly) elevated temperatures and pressures with high accuracy and then extrapolate to lower temperatures rather than measuring at lower temperature with low accuracy. Each of our experimental setups has a pressure range in which high-quality data can be obtained. Future measurements should be done preferably in the appropriate pressure range. We suggest using our data set of the homologous series of polyethylene glycols to determine the lower detection limit of saturation vapor pressures for each experimental setup, as well as using it for instrument calibration, for estimating systematic errors in experimental setups, and for comparison with vapor pressure estimation methods.

Data availability. All data of this study, shown in Figs. 2-8, are provided in Krieger (2017). 


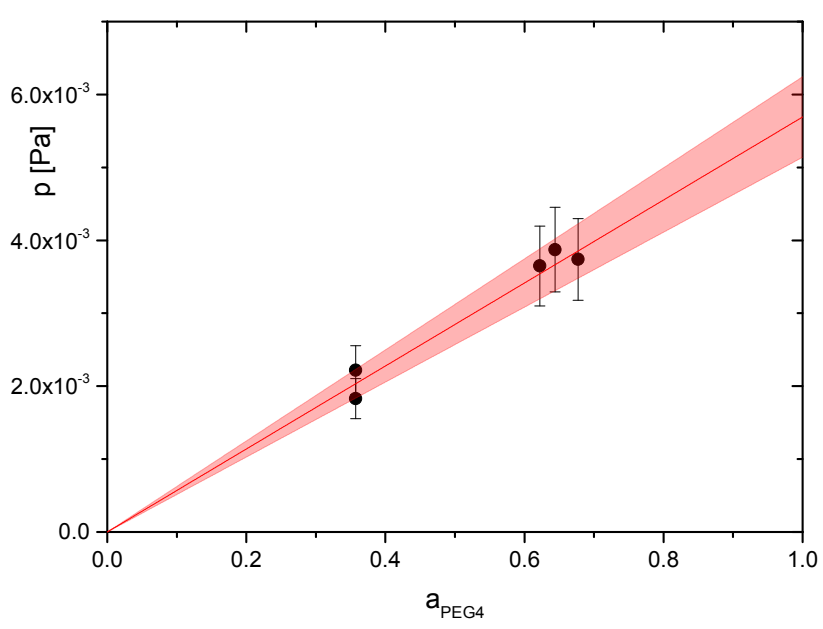

Figure A1. Partial pressures of PEG4 vs. PEG4 activity deduced from evaporation rates of single levitated, aqueous PEG4 particles in the EDB setup of Union College at a temperature of $286.5 \mathrm{~K}$. Black symbols: experiment data; red line and shaded area: linear fit to these data with the $95 \%$ confidence interval. Extrapolation to $a_{\text {PEG }}$ equal to 1 yields the saturation vapor pressure at this temperature, i.e., $p^{0}=(5.69 \pm 0.55) \times 10^{-3} \mathrm{~Pa}$ at this temperature.

\section{Appendix A: Data treatment of EDB data taken at elevated relative humidities}

Evaporation rates in the EDB setups were measured not only under dry conditions; some were also measured at elevated relative humidities. After the particle was equilibrated with respect to temperature and $\mathrm{RH}$, any change in size, $\mathrm{d} r^{2} / \mathrm{d} t$, was attributed to evaporative loss at a constant composition, and the partial pressure of the PEG, $p_{\mathrm{PEG}}$, under those conditions was calculated using Eq. (1) of Soonsin et al. (2010):

$p_{\mathrm{PEG}}=-\frac{1}{2} \frac{\mathrm{d} r^{2}}{\mathrm{~d} t} \frac{x \rho R T}{\left(x M_{\mathrm{PEG}}+(1-x) M_{\mathrm{H}_{2} \mathrm{O}}\right) D}$,

where $r$ is the particle radius, $x$ is the mole fraction of PEG, $\rho$ is the density of the condensed phase, $R$ is the gas constant, $M$ is molar mass, and $D$ is the diffusivity of the PEG vapor in the buffer atmosphere. The mole fraction of PEG in an aqueous particle was taken from the RH in the EDB (see Fig. 1) by assuming that the particle water activity is equivalent to measured RH, i.e., that the particle is homogeneous and in thermodynamic equilibrium (which is a good approximation as long as evaporation is sufficiently slow). Density was estimated by ideal mixing. As an example we show data obtained by the EDB setup of Union College at $286.5 \mathrm{~K}$ for PEG4 in Fig. A1.

Extrapolation of the data to a PEG activity equal to 1 yields the saturation pressure of PEG at this temperature.

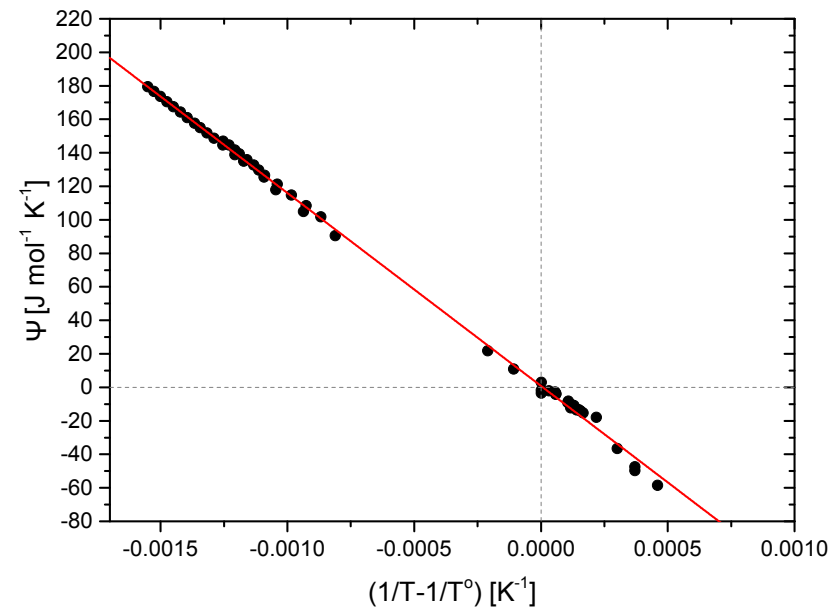

Figure B1. $\Psi$ vs. inverse, $\left(1 / T-\frac{1}{7} T^{\ominus}\right)$. Filled circles: all PEG3 data but Wise et al. (1950); red line: linear regression.

\section{Appendix B: Change in evaporation enthalpy with temperature}

Generally, the enthalpy of evaporation is a function of temperature. Let us analyze the data of PEG3 as an example following Chickos and Acree Jr. (2003). If the heat capacities of the liquid and gas phase are known $\left(C_{\mathrm{p}_{1}}\right.$ and $C_{\mathrm{pg}_{\mathrm{g}}}$, respectively), then the vaporization enthalpy, $\Delta H_{\text {vap }}\left(T^{\ominus}\right)$, at $T^{\ominus}=$ $298.15 \mathrm{~K}$ can be related to the experimental measurements by using Eq. (B1), generally referred to as Kirchhoff's equation:

$\Delta H_{\text {vap }}\left(T^{\ominus}\right)=\Delta H_{\text {vap }}(\bar{T})+\int_{T^{\ominus}}^{\bar{T}}\left(C_{\mathrm{p}_{1}}-C_{\mathrm{pg}_{\mathrm{g}}}\right) \mathrm{d} T$,

where $\bar{T}$ refers to the mean temperature of all measurements, which is equal to $357 \mathrm{~K}$ for our PEG3 data when calculating the mean of the inverse temperature range covered by the data. If we estimate $\left(C_{\mathrm{p}_{1}}-C_{\mathrm{p}_{\mathrm{g}}}\right)$ by using the method suggested by Chickos and Acree Jr. (2003) (which should be accurate to about $\pm 30 \mathrm{~J} \mathrm{~mol}^{-1} \mathrm{~K}^{-1}$ ),

$\left(C_{\mathrm{p}_{1}}-C_{\mathrm{p}_{\mathrm{g}}}\right)=\left(10.56+0.26 C_{\mathrm{p}_{1}}\right)$,

it yields $101 \pm 30 \mathrm{~J} \mathrm{~mol}^{-1} \mathrm{~K}^{-1}$ for the difference between heat capacity of the liquid and heat capacity of the gas phase when we take the value for the heat capacities of the liquid phase, $C_{\mathrm{p}_{1}}$, from Stephens and Tamplin (1979). Using Eq. (B1) with this average value for $\left(C_{\mathrm{p}_{1}}-C_{\mathrm{pg}_{\mathrm{g}}}\right)$ yields an increase to the uncorrected enthalpy of vaporization of $6.0 \pm 1.8 \mathrm{~kJ} \mathrm{~mol}^{-1}$ when using the temperature difference between mean temperature, $\bar{T}$, and $298.15 \mathrm{~K}$. Therefore, the enthalpy at the mean temperature of the measurements obtained by the linear regression, which is $\Delta H_{\text {vap }}(\exp , \bar{T})=$ $78.3 \pm 0.7 \mathrm{~kJ} \mathrm{~mol}^{-1}$, should be corrected to $\Delta H_{\text {vap }}^{\ominus}=84.3 \pm$ $1.9 \mathrm{~kJ} \mathrm{~mol}^{-1}$ at $298.15 \mathrm{~K}$. This corresponds to a shift of 
$7.5 \%$, which is clearly non-negligible. The magnitude is somewhat smaller for the higher-mass PEGs. In Table 2 we provide the enthalpies at both temperatures, $\bar{T}$ and $T^{\ominus}$.

Now we may integrate the Clausius-Clapeyron equation, Eq. (B3), in a more general form, by including Kirchhoff's equation, Eq. (B1), in the same manner as above, namely assuming a constant, temperature-independent heat capacity difference between liquid and gas phase.

$$
\begin{aligned}
\frac{\mathrm{d} p}{p} & =\frac{\Delta H_{\mathrm{vap}}(T)}{R} \frac{\mathrm{d} T}{T^{2}}, \text { with } \Delta H_{\mathrm{vap}}(T) \\
& =\Delta H_{\mathrm{vap}}\left(T^{\ominus}\right)-\left(C_{\mathrm{pl}}-C_{\mathrm{pg}_{\mathrm{g}}}\right)\left(T^{\ominus}-T\right)
\end{aligned}
$$

Integration of Eq. (B3) leads to

$$
\begin{aligned}
\ln \left(\frac{p}{p^{\ominus}}\right)= & -\frac{\Delta H_{\mathrm{vap}}\left(T^{\ominus}\right)-T^{\ominus}\left(C_{\mathrm{p}_{\mathrm{l}}}-C_{\mathrm{p}_{\mathrm{g}}}\right)}{R}\left(\frac{1}{T}-\frac{1}{T^{\ominus}}\right) \\
& +\frac{\left(C_{\mathrm{p}_{\mathrm{l}}}-C_{\mathrm{pg}_{\mathrm{g}}}\right)}{R} \ln \left(\frac{T}{T^{\ominus}}\right) .
\end{aligned}
$$

If we now plot $\Psi=\left\{R \ln \left(p / p^{\ominus}\right)-\left(C_{\mathrm{p}_{\mathrm{l}}}-C_{\mathrm{p}_{\mathrm{g}}}\right) \ln \left(T / T^{\ominus}\right)\right\}$ vs. $1 / T-1 / T^{\ominus}$, we expect a straight line with $\Psi(0)=0$. In Fig. B1 we show such a plot for the PEG3 data.

Clearly, considering the temperature dependence of the enthalpy of evaporation helps to reconcile the high-temperature data with those taken by us at roughly room temperatures. However, its effect close to $298 \mathrm{~K}$ is minimal by default if data at room temperature are available; see Eq. (B4). 
Competing interests. The authors declare that they have no conflict of interest.

Acknowledgements. Construction of the Union College EDB was supported by Union College, the American Chemical Society Petroleum Research Fund (ACS-PRF 54592-UNI6), and the US National Science Foundation National Science Foundation International Research Fellowship Program (US NSF IRFP \#1006117 and \#1100575). Acknowledgment is made to the Donors of the American Chemical Society for partial support of this research. Any opinions, findings, and conclusions or recommendations expressed in this material are those of the author(s) and do not necessarily reflect the views of the US National Science Foundation. We thank the CSC-IT Center for Science in Espoo, Finland, for computational resources. Nanna Myllys thanks the Doctoral Program in Atmospheric Sciences (ATM-DP) for financial support. Alexandra Marsh thanks EPSRC for DTA. Thomas Bannan and David Topping acknowledge support of the KEMS study by grants NE/M003531/1 and NE/N013794/1.

Edited by: Mingjin Tang

Reviewed by: two anonymous referees

\section{References}

Ambrose, D. and Hall, D. J.: Thermodynamic properties of organic oxygen compounds $\mathrm{L}$. The vapour pressures of 1,2-ethanediol (ethylene glycol) and bis(2-hydroxyethyl) ether (diethylene glycol), J. Chem. Thermodynam., 13, 61-66, 1981.

Baynes, T. S.: The Encyclopaedia Britannica, a Dictionary of Arts, Sciences, and General Literature, C. Scribner's Sons, New York, 9th Edn., 1878, vol. 7.

Becke, A. D.: Density-functional thermochemistry, 3. The role of exact exchange, J. Chem. Phys., 98, 5648-5652, 1993a.

Becke, A. D.: A new mixing of Hatree-Fock and local densityfunctional theories, J. Chem. Phys., 98, 1372-1377, 1993b.

Bilde, M., Svenningsson, B., Mønster, J., and Rosenørn, T.: Evenodd alternation of evaporation rates and vapor pressures of $\mathrm{C}_{3}-$ $\mathrm{C}_{9}$ dicarboxylic acid aerosols, Environ. Sci. Technol., 37, 13711378, 2003.

Bilde, M., Barsanti, K., Booth, M., Cappa, C. D., Donahue, N. M., Emanuelsson, E. U., McFiggans, G., Krieger, U. K., Marcolli, C., Topping, D., Ziemann, P., Barley, M., Clegg, S., Dennis-Smither, B., Hallquist, M., Hallquist, A. M., Khlystov, A., Kulmala, M., Mogensen, D., Percival, C. J., Pope, F., Reid, J. P., Ribeiro da Silva, M. A. V., Rosenoern, T., Salo, K., Soonsin, V., Yli-Juuti, T., Prisle, N. L., Pagels, J., Rarey, J., Zardini, A. A., and Riipinen, I.: Saturation vapor pressures and transition enthalpies of low-volatility organic molecules of atmospheric relevance: from dicarboxylic acids to complex mixtures, Chem. Rev., 115, 41154156, 2015.

Bird, R. B., Stewart, W. E., and Lightfoot, E. N.: Transport Phenomena, rev. 2nd Edn., John Wiley \& Sons, New York, 2007.

Booth, A. M., Markus, T., McFiggans, G., Percival, C. J., Mcgillen, M. R., and Topping, D. O.: Design and construction of a simple Knudsen Effusion Mass Spectrometer (KEMS) system for vapour pressure measurements of low volatility organics, At- mos. Meas. Tech., 2, 355-361, https://doi.org/10.5194/amt-2355-2009, 2009.

Booth, A. M., Barley, M. H., Topping, D. O., McFiggans, G., Garforth, A., and Percival, C. J.: Solid state and sub-cooled liquid vapour pressures of substituted dicarboxylic acids using Knudsen Effusion Mass Spectrometry (KEMS) and Differential Scanning Calorimetry, Atmos. Chem. Phys., 10, 4879-4892, https://doi.org/10.5194/acp-10-4879-2010, 2010.

Booth, A. M., Bannan, T., McGillen, M. R., Barley, M. H., Topping, D. O., McFiggans, G., and Percival, C. J.: The role of ortho, meta, para isomerism in measured solid state and derived sub-cooled liquid vapour pressures of substituted benzoic acids, RSC Adv., 2, 4430-4443, 2012.

Curme, G. O. and Johnston, F. (Eds.): Glycols, ACS Monograph, Reinhold Publishing Corporation, New York, 1952.

Chickos, J. S. and Acree Jr., W. E.: Enthalpies of vaporization of organic and organometallic compounds, 1880-2002, J. Phys. Chem. Ref. Data, 32, 519-878, 2003.

COSMOtherm: version C3.0, Release 17.02, COSMOlogic GmbH \& Co. KG, available at: http://www.cosmologic.de, last access: 22 December 2017

Crespo, E. A., Cost, J. M. L., Hanafiah, Z. B. M. A., Kurnia, K. A., Oliveira, M. B., Llovell, F., Vega, L. F., Carvalho, P. J., and Coutinho, J. A. P.: New measurements and modeling of high pressure thermodynamic properties of glycols, Fluid Phase Equilibr., 436, 113-123, 2017.

Davies, J. F., Haddrell, A. E., and Reid, J. P.: Time-resolved measurements of the evaporation of volatile components from single aerosol droplets, Aerosol Sci. Tech., 46, 666-677, 2012.

Davies, J. F., Miles, R. E. H., Haddrell, A. E., and Reid, J. P.: Influence of organic films on the evaporation and condensation of water in aerosol, P. Natl. Acad. Sci USA, 110, 8807-8812, 2013.

Davis, E. J., Buehler, M. F., and Ward, T. L.: The double-ring electrodynamic balance for microparticle characterization, Rev. Sci Instrum., 61, 1281-1288, 1990.

Eckert, F. and Klamt, A.: Fast solvent screening via quantum chemistry: COSMO-RS approach, AlChE J., 48, 369-385, 2002.

Ehn, M., Kleist, E., Junninen, H., Petäjä, T., Lönn, G., Schobesberger, S., Dal Maso, M., Trimborn, A., Kulmala, M., Worsnop, D. R., Wahner, A., Wildt, J., and Mentel, Th. F.: Gas phase formation of extremely oxidized pinene reaction products in chamber and ambient air, Atmos. Chem. Phys., 12, 5113-5127, https://doi.org/10.5194/acp-12-5113-2012, 2012.

Emanuelsson, E. U., Tschiskale, M., and Bilde, M.: Phase state and saturation vapor pressure of submicron particles of mesoerythritol at ambient conditions, J. Phys. Chem. A, 120, 71837191, 2016.

Frosch, M., Zardini, A. A., Platt, S. M., Müller, L., Reinnig, M.-C., Hoffmann, T., and Bilde, M.: Thermodynamic properties and cloud droplet activation of a series of oxo-acids, Atmos. Chem. Phys., 10, 5873-5890, https://doi.org/10.5194/acp10-5873-2010, 2010.

Gallaugher, A. F.: The Physical and Chemical Properties of the Polyethylene Glycols and Their Derivatives, PhD Thesis, McGill University, Montreal, Canada, 1932.

Gallaugher, A. F. and Hibbert, H.: Studies on reactions relating to carbohydrates and polysaccharides. XLIX. Molecular weight, molar refraction, freezing point and other properties of the 
polyethylene glycols and their derivatives, J. Am. Chem. Soc., 58, 813-816, 1936.

Gallaugher, A. F. and Hibbert, H.: Studies on reactions relating to carbohydrates and polysaccharides. LIV. The surface tension constants of the polyethylene glycols and their derivatives, J. Am. Chem. Soc., 59, 2514-2521, 1937.

Glantschnig, W. J. and Chen, S.-H.: Light scattering from water droplets in the geometrical optics approximation, Appl. Optics, 20, 2499-2509, 1981.

Grenier-Loustalot, M.-F., Potin-Gautier, M., and Grenier, P.: Applications Analytiques de la Mesure des Tensions de Vapeur par Saturation d'un Gaz Inerte Cas des Alcanes Normaux et des Polyethyleneglycols, Anal. Lett., 14, 1335-1349, 1981.

Hales, J. L., Cogman, R. C., and Frith, W. J.: A transpirationg.l.c. apparatus for measurement of low vapour concentration, J. Chem. Thermodynam., 13, 591-601, 1981.

Hehre, W. J., Ditchfield, R., and Pople, J. A.: Self-Consistent Molecular Orbital Methods. XII. Further Extensions of Gaussian-Type Basis Sets for Use in Molecular Orbital Studies of Organic Molecules, J. Chem. Phys. 56, 2257-2261, https://doi.org/10.1063/1.1677527, 1972.

Huisman, A. J., Krieger, U. K., Zuend, A., Marcolli, C., and Peter, T.: Vapor pressures of substituted polycarboxylic acids are much lower than previously reported, Atmos. Chem. Phys., 13, 66476662, https://doi.org/10.5194/acp-13-6647-2013, 2013.

Jakubczyk, D., Derkachov, G., Do Duc, T., Kolwas, K., and Kolwas, M.: Coefficients of evaporation and gas phase diffusion of low-volatility organic solvents in nitrogen from interferometric study of evaporating droplets, J. Phys. Chem. A, 114, 34833488, 2010.

Jimenez, J. L., Canagaratna, M. R., Donahue, N. M., Prevot, A. S. H., Zhang, Q., Kroll, J. H., DeCarlo, P. F., Allan, J. D., Coe, H., Ng, N. L., Aiken, A. C., Docherty, K. S., Ulbrich, I. M., Grieshop, A. P., Robinson, A. L., Duplissy, J., Smith, J. D., Wilson, K. R., Lanz, V. A., Hueglin, C., Sun, Y. L., Tian, J., Laaksonen, A., Raatikainen, T., Rautiainen, J., Vaattovaara, P., Ehn, M., Kulmala, M., Tomlinson, J. M., Collins, D. R., Cubison, M. J., Dunlea, E. J., Huffman, J. A., Onasch, T. B., Alfarra, M. R., Williams, P. I., Bower, K., Kondo, Y., Schneider, J. Drewnick, F., Borrmann, S., Weimer, S., Demerjian, K., Salcedo, D., Cottrell, L., Griffin, R., Takami, A., Miyoshi, T., Hatakeyama, S., Shimono, A., Sun, J. Y., Zhang, Y. M., Dzepina, K., Kimmel, J. R., Sueper, D., Jayne, J. T., Herndon, S. C., Trimborn, A. M., Williams, L. R., Wood, E. C., Middlebrook, A. M., Kolb, C. E., Baltensperger, U., and Worsnop, D. R.: Evolution of organic aerosols in the atmosphere, Science, 326, 1525-1529, https://doi.org/10.1126/science.1180353, 2009.

Krieger, U. K., Marcolli, C., and Reid, J. P.: Exploring the complexity of aerosol particle properties and processes using single particle techniques, Chem. Soc. Rev., 41, 6631-6662, 2012.

Krieger, U. K.: A reference data set for validating vapor pressure measurement techniques: Homologous series of polyethylene glycols, https://doi.org/10.3929/ethz-b-000168628, 2017.

Kurtén, T., Tiusanen, K., Roldin, P., Rissanen, M., Luy, J. N., Boy, M., Ehn, M., and Donehue, N. M.: alpha-pinene autoxidation products may not have extremely low saturation vapor pressures despite high O : C ratios, J. Phys. Chem. A, 120, 25692582, 2016.
Lugg, G. A.: Diffusion coefficients of some organic and other vapors in air, Anal. Chem., 40, 1072-1077, 1968.

Marcolli, C., Luo, B. P., and Peter, T.: Mixing of the organic aerosol fractions: liquids as the thermodynamically stable phases, J. Phys. Chem. A, 108, 2216-2224, 2004.

Ninni, L., Camargo, M. S., and Meirelles, A. J. A.: Water activity in poly(ethylene glycol) aqueous solutions, Thermochim. Acta, 328, 169-176, 1999.

O’Meara, S., Booth, A. M., Barley, M. H., Topping, D., and McFiggans, G.: An assessment of vapour pressure estimation methods, Phys. Chem. Chem. Phys., 16, 19453-19469, 2014.

Poling, B. E., Prausnitz, J. M., and O'Connell, J. P.: The Properties of Gases and Liquids, McGraw-Hill, New York, 2001.

Riipinen, I., Svenningsson, B., Bilde, M., Gaman, A., Lehtinen, K. E. J., and Kulmala, M.: A method for determining thermophysical properties of organic material in aqueous solutions: succinic acid, Atmos. Res., 82, 579-590, 2006.

Rovelli, G., Miles, R. E. H., and Reid, J. P.: Accurate measurements of aerosol hygroscopic growth over a wide range in relative humidity, J. Phys. Chem. A, 120, 4376-4388, 2016.

Schäfer, A., Huber, C., and Ahlrichs, R.: Fully optimized contracted Gaussian basis sets of triple zeta valence quality for atoms $\mathrm{Li}$ to $\mathrm{Kr}$, J. Chem. Phys., 100, 5829-5835, https://doi.org/10.1063/1.467146, 1994.

Soonsin, V., Zardini, A. A., Marcolli, C., Zuend, A., and Krieger, U. K.: The vapor pressures and activities of dicarboxylic acids reconsidered: the impact of the physical state of the aerosol, Atmos. Chem. Phys., 10, 11753-11767, https://doi.org/10.5194/acp-10-11753-2010, 2010.

Wavefunction Inc.: Spartan'14 version 1.1.9, Irvine, CA, 2014.

Steele, W. V., Chirico, R. D., Knipmeyer, S. E., and Nguyen, A.: Measurements of vapor pressure, heat capacity, and density along the saturation line for $\varepsilon$-caprolactam, pyrazine, 1,2-propanediol, triethylene glycol, phenyl acetylene, and diphenyl acetylene, J. Chem. Eng. Data, 47, 689-699, 2002.

Steffen, C., Thomas, K., Huniar, U., Hellweg, A., Rubner, O., and Schoer, A.: TmoleX - a graphical user interface for TURBOMOLE, J. Comput. Chem. 31, 2967-2970, 2010.

Stephens, M. A. and Tamplin, S. W.: Saturated liquid specific heats of ethylene glycol homologues, J. Chem. Eng. Data, 24, 81-82, 1979.

Topping, D., Barley, M., Bane, M. K., Higham, N., Aumont, B., Dingle, N., and McFiggans, G.: UManSysProp v1.0: an online and open-source facility for molecular property prediction and atmospheric aerosol calculations, Geosci. Model Dev., 9, 899914, https://doi.org/10.5194/gmd-9-899-2016, 2016.

TURBOMOLE V7.1 2016: A development of University of Karlsruhe and Forschungszentrum Karlsruhe GmbH, 1989-2007, TURBOMOLE GmbH, since 2007, available at: http://www. turbomole.com (last access: 22 December 2017), 2016.

Wise, H., Puck, T. T., and Failey, C. F.: Studies in vapor-lquid equilibria II: The binary system triethylene glycole-water, J. Phys. Chem., 54, 734-741, 1950.

Zardini, A. A., Krieger, U. K., and Marcolli, C.: White light Mie resonance spectroscopy used to measure very low vapor pressures of substances in aqueous solution aerosol particles, Opt. Express, 14, 6951-6962, 2006. 
Zardini, A. A., Riipinen, I., Koponen, I. K., Kulmala, M., and Bilde, M.: Evaporation of ternary inorganic/organic aqueous droplets: sodium chloride, succinic acid and water, J. Aerosol Sci., 41, 760-770, 2010. 